\title{
Developing a hospital information strategy: a clinician's view
}

\author{
Christopher Bunch
}

\section{The proposition}

"Your mission - should you decided to accept it is to develop an information strategy for your hospital. We are committed to letting you do this yourselves - it will give you a sense of ownershipbut just to help you, we have some guidelines that specify in great detail just how you are to go about it. Funding? Yes, well-our land sales are rather less than we had hoped for this year, but you do have a cost improvement target, and there is some money for the resource management initiative. There's also some for medical audit, but we've handed that over to your district. And of course we have expertise in information technology you can use on a consultancy basis. Experience? Yes, of course they're experienced. They've been working for us for years...."

Offered the above mission, any sane person might reasonably let the tape auto-destruct and simply drive home. The only other rational course is to shut one's eyes and start from first principles.

\section{The principles}

In developing an information strategy for the John Radcliffe Hospital we have tried to follow certain basic principles. Many of these-such as good project management and adherence to accepted technical standards-should go without saying. Some are perhaps less immediately obvious and are worth exploring in more detail.

\section{INFORMATION SYSTEMS SHOULD SUPPORT RATHER THAN CONSTRAIN}

The value of information is most fully realised when it helps one to achieve one's objectives. It follows that a successful information strategy cannot emerge unless objectives are clear and the strategy supports rather than hinders any organisational change that may be required to achieve those objectives. This is not especially contentious, but the environment is changing, and in a large organisation such as the NHS there is plenty of scope for objectives to conflict. The hospital service is currently experiencing the most far reaching cultural and organisational changes since the inception of the NHS. These have largely been driven by pressure for greater accountability, both for the use of public funds but also to the patient. This need is driven, on the one hand, by spiralling healthcare costs and, on the other, by a growth in patients' expectations coupled with a disturbing increase in their willingness to resort to litigation when these are not fulfilled.

In structural terms the major change is from a bureaucratic, administered organisation with strong but separate vertical administrative and professional hierarchies to a more pro-active, managed organisation with a greater emphasis on flexibility and teamwork between doctors, nurses, managers, and other healthcare professionals. This implies a flatter structure and is illustrated by the development of clinical directorates

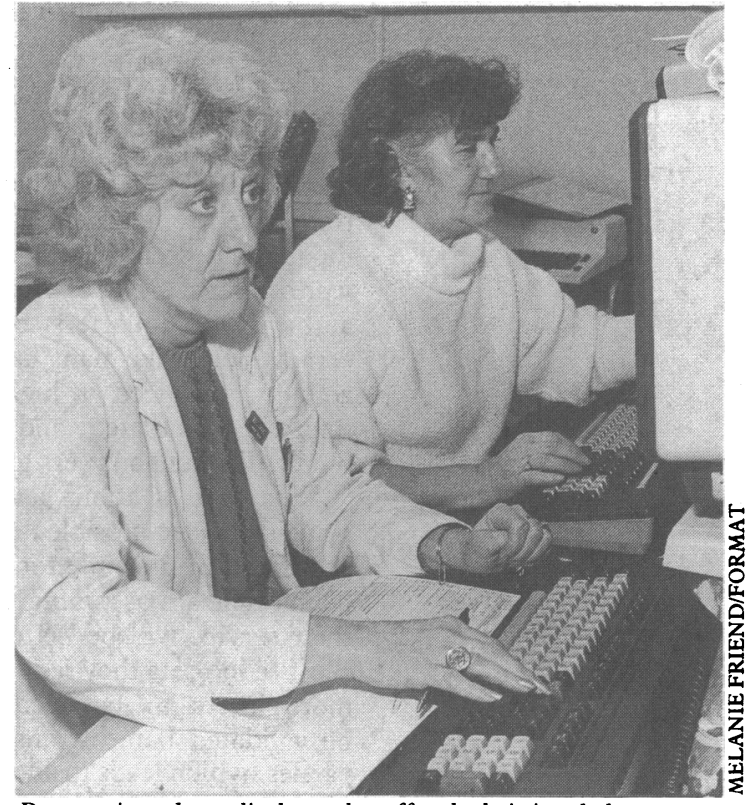

Data are input by medical records staff and admission clerks

and specialty management teams. In process terms, however, change has been slower and alterations in the flow of hospital funds, the separation of purchaser and provider, and the introduction of service agreements or contracts highlight the need for clinical teams to plan their services and resource requirements in advance, rather than assuming everything will be all right (and complaining when it's not).

The implications for information strategy development are profound. Hospitals, and more especially their clinical or service teams, will need to produce realistic, costed service plans. For this they will need accurate information about patient flows, the costs of investigations and treatment, etc. Assuming for the moment that they will achieve the necessary funding through contracts, they must then be able to monitor their activity and resource consumption in a timely fashion so that they can take action if things don't go according to plan.

Our experience is that existing information systems have difficulty in providing this kind of information and may thereby hinder the processes of service definition and planning. What may be required is a fundamental change in the way in which hospital data are collected in future.

WHOSE DATA ARE THEY, ANYWAY?

Traditionally, hospitals have been required to collect data for transmission to their district health authority and beyond. Existing systems (often manual) are not necessarily geared to providing information for internal consumption, and hospital management has often had to rely on digests of information being returned to them at a later date. Not surprisingly, confidence in the accuracy and validity of this information is often low. 
A local example may serve to illustrate the difficulty. Our hospital makes use of remote patient activity system, which is located and managed at regional headquarters and covers all local hospitals. At present it tracks inpatient and accident and emergency activity but not outpatients. Data are input by medical records staff and admission clerks: there is no direct access from wards, which must telephone details of patient movements to a central office. Straightforward admissions and discharges are reasonably accurately recorded, but consultant to consultant and interhospital transfers are not. Diagnostic codes are added retrospectively by coders at the regional health authority, working from "diagnostic text strings" extracted by staff in medical records departments: the accuracy in one recent validation exercise was as low as $38 \%$.

The patient activity system cannot be interrogated: simple printouts are available to wards and consultants indicating which patients they currently have in the hospital (as if they didn't know). Periodically tapes are transferred to another computer running a relational model that seems to bear little relation to the real world. This can be interrogated at district health authority headquarters, but not by the hospital, and some reports take many hours to run. The information actually produced is highly dependent on how the query is formulated, and it is sometimes possible to obtain different answers to the same basic question.

This state of affairs leads us to another important principle: when possible those requiring the information should be responsible for collecting the data. Clinical teams that are assuming responsibility for managing their service will be better served if they are able to capture the data they require themselves. These are far more likely to be accurate and can more easily be validated before transmission to other interested parties, which leads to another issue.

\section{DOES EVERYONE REALLY NEED TO KNOW EVERYTHING?}

There is a pervasive assumption that the advent of cheap and sophisticated information systems will enable anyone to find out anything about anyone anywhere. Leaving aside issues such as confidentiality and personal freedom - which are extremely important none the less-do regional health authorities really need on line access to all their hospitals' information systems? What will they do with it? Is it sensible for purchasing district health authorities to roam around inside their providers' systems? (This has actually been happening in our region.)

One of the main reasons that large and complex

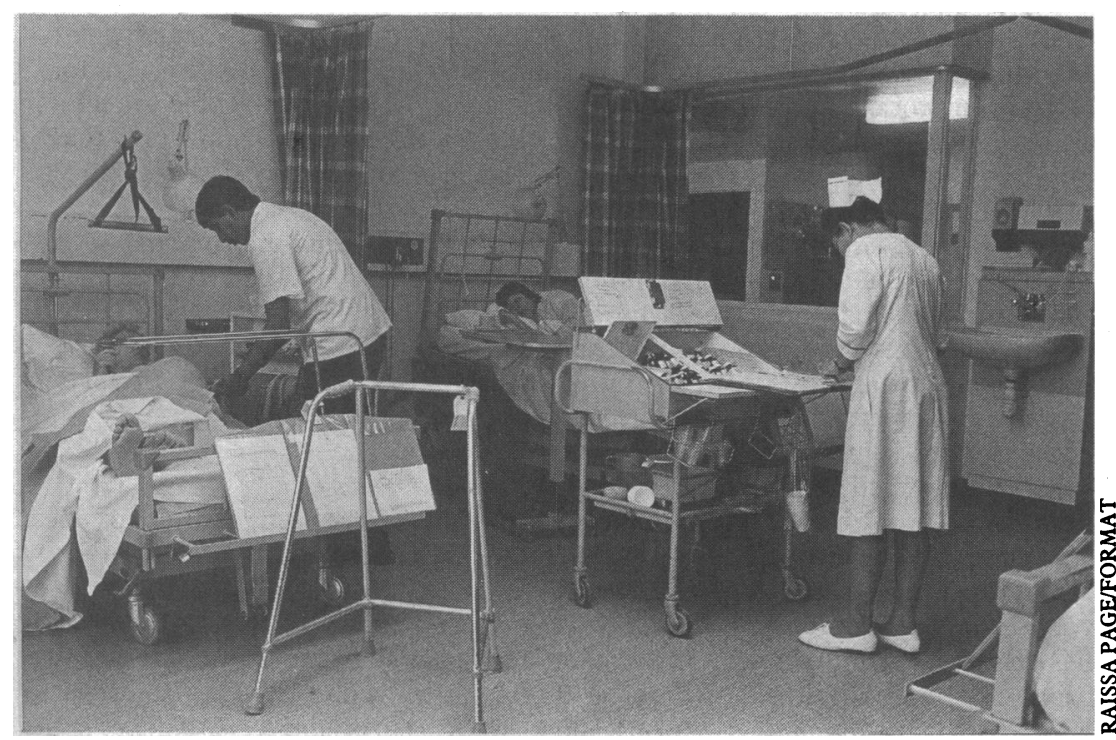

Clinical activity is the main business of most hospitals organisations need to decentralise is simply to facilitate information management. In the 1960 s it was predicted that computer technology would actually lead to centralisation: management would have access to all the information required to make all the necessary decisions. The trouble is that the amount of information turns out to be too large to handle, and it becomes too difficult to see the wood for the trees. What is required in the NHS is for each part of the organisation to be really clear about what it needs to know and to obtain this information in the simplest way possible: a regular printed summary may well suffice. Electronic forms of communication may become indispensable in some areas but should always be the servant, not the master.

\section{THE CLINICIAN'S NEEDS ARE IMPORTANT TOO}

We are currently being encouraged to take a "business" view of information systems and requirements. There is, however, a danger of taking the business led approach too literally, concentrating on resource and financial information at the expense of clinical needs. Clinical activity is, after all, the main business of most hospitals.

Clinicians need timely information to manage their patients effectively, and with decreasing lengths of hospital stay it becomes all the more important that patient management should not be hindered by lack of the necessary information. Also, though many clinicians are gradually accepting the need to become more involved in managing their services, few see the point of major investments in information systems that provide management information but do little to facilitate clinical activity. The application of information technology to clinical practice is poorly developed: simple office management technology is yet to reach many consultant practices, and the provision of clinical information by computer has often been eschewed in favour of financial and administrative needs.

The reasons for this are complex but worth exploring. Firstly, to be useful, information to support patient management has to be available to clinicians (doctors and nurses) more or less in real time, whereas information for service management and audit can be retrospective (though preferably not unduly historical). Real time information systems are more complex to design and manage. Secondly, clinical practice and decision making are poorly understood by managers and information specialists, and there are few clinicians who are both managerially competent and computer literate. Clinical information has thus had low priority in most hospital information system implementations. A third reasons is that historically most major NHS information technology projects have been driven by a perceived need to provide hospital activity information to outside organisations such as the district health authority, regional health authority, and central government, in line perhaps with a central, hierarchical administration. Even hospital departmental systems have had little to offer the clinician. Our hospital was one of the first in the country to install a laboratory computer, yet in most instances we still write requests by hand and wait for the results to be returned by the internal mail.

It is important that these deficiencies should not be ignored. Many clinicians, aware from colleagues in North America what could be available, are acquiring sophisticated personal data management systems for their own practices, funded from soft money or from funding earmarked for audit. These initiatives fall outside the normal channels for developing hospital information systems and can lead to problems with integration when clinicians want their systems linked into hospital systems or require hospital staff to rekey data on their behalf. It would be far better if clinical 
needs could be satisfied as part of an overall hospital strategy.

\section{THE FAMILY SILVER}

A reasonable principle must be to make the best possible use of existing investment in information systems. There is a limit, however, to how far this ideal can be pursued, and there will be many hospitals that are largely uncomputerised that may therefore have many more degrees of freedom than those that are saddled with out of date technology. Information strategy and organisational development should not be unduly constrained by previous investment, however large. Unlike the family silver, it may have little resale value. The changes in the NHS are profound enough to render many systems inadequate, and the costs of upgrading or modifying some must be carefully balanced against possible longer term benefits of replacing them altogether.

\section{The practice}

The John Radcliffe Hospital has been a resource management site since 1989 . Unlike many such sites, which have moved quickly to acquire case mix management, nurse management, and other systemssometimes with little thought as to how they would fit in to an overall strategy - we have concentrated first on service and organisational development. This has involved identifying 60-70 service areas, or service delivery units. A typical service delivery unit might be a specialty ward, a laboratory, the intensive therapy unit, theatres, etc. Each service delivery unit will typically be responsible for delivering a definable set of services to patients or to other such units and will require various resources, some of which it will own and some of which it will obtain, by agreement, from other units.

Each service delivery unit is managed by a lead clinician (typically a consultant) and a nurse (or equivalent) manager. Together they are responsible for developing and managing the unit's service plan. Service delivery units with similar "interests" are grouped into service centres, which are roughly analogous to clinical directorates. The service centre has a consultant (or equivalent) chairman and a full time service manager: its role is to coordinate, support, and monitor the activity of its constituent service delivery units and provide an interface with senior management (finance, personnel, contracting, etc). The service centre chairmen together with senior management meet monthly as the hospital board, which is concerned with matters of strategic direction and policy. Service managers and senior management meet fortnightly as the operational board, which ensures that hospital policy is put into operation and that its targets are met.

The organisational change is emphasised in detail because it has major implications for information strategy, some of which have been covered above. Given that the information strategy should support objectives, it is clear that each level-hospital boards, service centres, and service delivery units - will have particular requirements, all of which need to be taken into account.

\section{STEERING THE STRATEGY}

The hospital board has a standing committee - the Information Strategy Steering Group-composed of senior management, clinicians, and information technology specialists. The committee has a number of task groups, each responsible for working up a particular aspect of the overall strategy: in this way we have been able to involve a wide range of hospital staff. Current task groups are responsible for: (1) information requirements definition-working closely with pilot service delivery units in developing service plans and determining what information they will need to monitor service delivery; (2) technical standards-ensuring that systems conform as appropriate to national and local standards; (3) data standards-defining data models and datasets and providing consistency of widely used data such as general practitioner code lists; (4) information protection-developing hospital policy, standards, and procedures for compliance with the Data Protection Act as well as ensuring the safety of hospital information and data; (5) training-defining the skills required by key personnel and arranging the necessary training.

\section{EMERGING CONCEPTS}

It is perhaps a little premature to second guess the strategy in detail. What is already clear is that service delivery units need simple processes for capturing activity data and using these to monitor their service delivery. We have thus prototyped a simple personal computer based system to manage this as well as providing some support for service planning. The first step will also ensure that accurate data are available for activities as diverse as contract management and clinical audit.

The next step will be to provide a central data server, which will remove the need for service delivery unit systems to store basic patient details locally. It will also maintain spell records (a spell is an instance of delivery of a particular service by a service delivery unit: we expect it will in future form a more rational currency for service agreements than consultant episodes and similar measures that have little relevance to clinical practice) and event records (an event is an instance of consumption of a measurable resource; examples include bed days, outpatient visits, operations, laboratory tests, $x$ ray examinations, etc). The data server will in effect be the repository for the hospital's public data - that is, data which may need to be accessible at a variety of levels. Individual service delivery unit or service centre based systems may retain private data - that is, data that are of interest only to the individual service. These may include research or audit data or operational data such as theatre scheduling or clinic booking.

The separation of global, public data from local, private data reflects the organisational model and makes it easier to shift the responsibility for data collection from central clerical staff to service delivery staff by ensuring that the latter have systems that they need while avoiding the need for rekeying basic data when the same patients encounter different services. A central data server will also provide consistent data for contract management and will help the hospital fulfil its obligations to provide information to purchasers, regional health authorities, etc.

The service based model of resource managementin which resource consumption is linked to instances of delivery of defined services-will, we believe, be superior to models based on case mix analysis, where case mix is primarily defined by diagnostic categories. In our model case mix analysis allows the examination of variances in resource consumption of individual services to promote improvements in efficiency as well as effectiveness. The analysis will encompass a wide range of criteria, including type of patient, diagnosis, severity of illness, complications, treatment protocol, etc.

\section{The problems}

It would be misleading to suggest that developing a hospital information strategy is painless. The NHS reforms have made the hospital a volatile environment, and for a variety of reasons many staff still find themselves uncomfortable with some aspects of the reforms. In our experience most are prepared to rise to the challenge and see potential benefits from being in a 
position to manage their own services, provided the resources are somewhere approaching adequate. One of the most important resources is information: without it we grope in the dark and have fair reason to blame the system when things go wrong; with it we can begin to make rational decisions, develop a more effective service, and assume a greater degree of responsibility.

A curious aspect in which a hospital information strategy is potentially constrained is the separation of funding for medical audit and resource management. Our belief is that the two go hand in hand, especially when clinical staff are being encouraged to take responsibility for managing their clinical services. Our experience in developing clinical management teams at the ward rather than directorate level suggests that this can lead to far better teamwork between doctors and nurses than might otherwise be the case. Since both professions are managing the same patients this must be to the patients' advantage. Encouraging separate investment in medical audit and nurse management systems does not help this and seems set to perpetuate professional rivalries. Both professions currently capture similar patient data in their respective manual records, and both initiate separate care plans for the same patients - often without reference to each other. Perpetuating this division of labour in hardware and software makes little sense.
Perhaps the greatest problem is that although hospitals are being encouraged to develop their own strategies, their room for manoeuvre is limited. Guidelines-initially supportive in intent-become increasingly prescriptive and seemingly less relevant. Funding is earmarked for specific system developments whether or not they eventually form part of a carefully developed strategy. It is as though a great scientist having initiated his experiment and impatient for the results begins to write them up while turning a blind eye to the actual outcome.

A simple approach to an information strategy would be to ignore the clinical coalface, devolve hardly at all, and ensure that contact minimum datasets and other externally required information are delivered by installing central contract and case mix systems fed by the traditional army of clerks. Boxes could be ticked and paymasters kept happy-for a while. This would, however, be an extremely short term view and would do little to ensure the continuing good will and involvement of those who actually treat the patients.

I am especially grateful to Stephen Ranger, of OASiS, for his indefatigable support and for ensuring that our thoughts did not completely transgress the bounds of possibility, and to David Feeney and Guy Fitzgerald, of Templeton College, Oxford, for useful insights and advice.
British Medical Journal, London WC1H 9JR

Jane Smith, deputy editor

BMF 1992;304:1036-9

\section{The New NHS: first year's experience}

\section{West Suffolk: a changing world}

\section{Jane Smith}

You might expect West Suffolk to have ridden the first year of the reforms well. As a predominantly rural district with one main general hospital, comprehensive community services, and good general practices, its potential for chaos was always much less than that of places like Newcastle upon Tyne (4 April, p 907) or East Birmingham (described in next week's $B M \mathcal{F}$ ). And, indeed, the district and its two directly managed units (the acute unit based at West Suffolk Hospital in Bury St Edmunds and the community health unit), have ridden it well. Contracts have been met, waiting lists have been reduced, no extracontractual referrals have been refused, both district and units ended the year in financial balance, and both units have applied to become trusts. Nevertheless, two events have overshadowed the first year of the reforms and will continue to do so: the possibility of West Suffolk district merging with East Suffolk and the change of use of Newmarket Hospital.

\section{The merger}

One of the main lessons learnt by the health authority during the first year has been that it isn't big enough to do its job properly. As Jane Rutherford, director of planning and personnei, explained, West Suffolk is only just big enough to set up the framework for purchasing - to establish contracts, monitor them, and measure activity. "There is no extra capacity to maintain a dialogue with general practitioners and to set up teams to delve into particular aspects of care... . We are only just surviving."

The merger may be seen as inevitable by district officers, but others have mixed feelings. Many people remember with suspicion the old Suffolk Area Health Authority. They felt then that East Suffolk's bigger hospital in Ipswich sucked in more than its share of resources and they fear the same again. So much so that Grant Elliott, now director of finance of both authorities, has pledged himself, if appointed director of finance of a new authority, to ensure that the people of West Suffolk receive their fair share of resources.

The effect of the merger has been most dramatic at West Suffolk Hospital: it has swung the consultants behind the hospital's trust application. "The cosy relationship [with West Suffolk Health Authority] will go, and then it'll all come down to cost," said one. Some years ago there was a proposal to concentrate ear, nose, and throat surgery at Ipswich; the consultants fought hard to prevent it and would do so again. If ear, nose, and throat surgery goes, they reason, other services will follow and the hospital will be left simply providing outpatient services for Ipswich and Addenbrooke's. "We'll become an irritant to Ipswich just as Newmarket has become an irritant to West Suffolk," another said.

Neither general practitioners nor district officers think that is likely. Bury St Edmunds' natural communications are with its hinterland, the small towns on roads that radiate from it, and the "purchasers" think that patients simply would not go easily to Ipswich. "The people of West Suffolk wouldn't stand for it," said Dr Ted Cockayne, a general practitioner in the east of the district, nearest to Ipswich, but who nevertheless refers nearly all his patients to Bury.

\section{Newmarket}

Newmarket Hospital has been a "problem" for the past nine years, and without the reforms some reckon that it would have been for a good few more yet. Instead the internal market has forced a decision.

Newmarket Hospital is a small acute unit with high costs and a reputation for friendliness that has 